ORIGINAL ARTICLE

\title{
Hip passive range of motion and frequency of radiographic hip osteoarthritis in former elite handball players
}

\author{
M L'Hermette, G Polle, C Tourny-Chollet, F Dujardin
}

Br J Sports Med 2006;40:45-49. doi: 10.1136/bjsm.2005.019026

See end of article for authors' affiliations

Correspondence to:

Mr L'Hermette, Facultè des Sciences du Sport, Universitè de Roven Boulevard Siegfried'Mont Saint Aignan, Roven 76 821, France; mlhermette@ yahoo.fr

Accepted 6 June 2005

\begin{abstract}
Objective: To establish the relation between handball playing, passive hip range of motion (ROM), and the development of radiological hip osteoarthritis $(\mathrm{OA})$ in former elite handball players. Two related issues are addressed: (a) the relation between long term elite handball playing and the incidence of hip OA; $(b)$ the relations between hip ROM, OA, and pain.

Methods: Data on 20 former elite handball players and 39 control subjects were collected. A questionnaire yielded personal details, loading patterns during physical activity, and previous lower limb joint injury. Bilateral radiographs were analysed to diagnose and classify hip OA. Passive hip ROM was measured bilaterally with a goniometer.

Results: A close relation was found between long term elite handball practice and the incidence of hip OA: $60 \%$ of the handball players were diagnosed with OA in at least one of the hip joints compared with $13 \%$ of the control subjects. Passive ROM measured in the handball players was significantly lower for hip flexion and medial rotation and higher for abduction, extension, and lateral rotation than the control values. The handball players with OA reported less pain in the hip joints during daily activities than the control subjects with OA.

Conclusion: The risk of developing premature hip OA seems high for retired handball players and significantly greater than for the general population. Pain and discomfort represent two difficult diagnostic challenges to the sports physician, as the repetitive nature of movements that are specific to handball can lead to alterations that are rarely seen in the general population.
\end{abstract}




\begin{tabular}{|c|c|c|c|}
\hline & $\begin{array}{l}\text { Handball } \\
\text { players }(n=20)\end{array}$ & Controls $(n=39)$ & p Value* \\
\hline \multicolumn{4}{|l|}{ Age (years) } \\
\hline Mean (SD) & $44.9(4.7)$ & $42.5(4.7)$ & \multirow[t]{2}{*}{0.06} \\
\hline Range & $37-54$ & $35-53$ & \\
\hline \multicolumn{4}{|l|}{ Height $(\mathrm{cm})$} \\
\hline Mean (SD) & $177.8(6.7)$ & $174.6(8.2)$ & \multirow[t]{2}{*}{0.13} \\
\hline Range & $168-192$ & $150-190$ & \\
\hline \multicolumn{4}{|l|}{ Weight (kg) } \\
\hline Mean (SD) & 80.8 (11.2) & $75.2(16.0)$ & \multirow[t]{2}{*}{0.16} \\
\hline Range & $65-100$ & $43-110$ & \\
\hline \multicolumn{4}{|c|}{ Body mass index $\left(\mathrm{kg} / \mathrm{m}^{2}\right)$} \\
\hline Mean (SD) & $25.1(3.0)$ & $23.9(3.7)$ & \multirow[t]{2}{*}{0.19} \\
\hline Range & $20-32$ & $17-32$ & \\
\hline \multicolumn{4}{|c|}{ Training volume (hours/week) } \\
\hline Mean (SD) & $6(1.4)$ & $0.3(1.1)$ & \multirow[t]{2}{*}{$<0.0001$} \\
\hline Range & $4-9$ & $0-5$ & \\
\hline \multicolumn{4}{|c|}{ Lifetime handball training (years) } \\
\hline Mean (SD) & $24.8(7.1)$ & $0.5(1.9)$ & \multirow[t]{4}{*}{$<0.0001$} \\
\hline Range & $15-40$ & $0-10$ & \\
\hline \multicolumn{3}{|l|}{ Heavy worker } & \\
\hline$\%(\mathrm{No})$ & $19(4)$ & $51.2(21)$ & \\
\hline
\end{tabular}

Information on these factors was obtained from personal interviews and radiographic examination. Table 1 presents the characteristics of both groups. All study participants gave their informed consent before testing began.

\section{Interview}

The questionnaire was divided into sections designed to accrue information on risk factors for hip OA: personal details (birth date, first official elite game, retirement from elite handball, playing position), lifetime occupational loading, years and hours a week of athletic training, lower limb pain or injury, family medical history, and current medical conditions of lower limb joints (medical treatments and dysfunction in lower limb joints). The interview was based on the questionnaire responses and used open ended questions. The method is described in detail elsewhere. ${ }^{16}$ The main characteristics and background factors were selected (table 1).

\section{Hip radiography}

All the subjects had a radiographic examination of the hip. The joint was internally rotated, with an angle of $15-20^{\circ}$ subtended between the insides of the feet, which is a position consistent with normal functional or cyclical loading of the joint. The anatomical hip values were established from analysis at a 1:1 scale on radiographs obtained during weight bearing in the coronal plane using the Lequesne false profile. The radiographic criteria were used to discriminate between healthy and degenerative hips. The radiographic classification of Kellgren and Lawrence, ${ }^{23}$ with OA scored on a scale of 0 to 4 , was followed to diagnose the severity of the disease. The radiographs were also used to determine the JSW and its localisation, as well as to detect osteophytes, osseous cysts, and subchondral sclerosis. This measurement provides information on the state of the tissue: both its thickness and its compressibility when under a load. JSW measurements are more reliable when radiographs are taken with the hip joint bearing weight, as this ensures that the femoral head is pressing into the acetabulum. ${ }^{9}$ The radiographs were blind analysed by the fourth author (FD) after all had been collected. The classification, material, and method were unchanged between the analysis sessions.

\section{Clinical examinations and functional measurements} The clinical examinations and quantitative measurements were performed by the second author (GP). The passive ROM was measured bilaterally for the hip and knee with a goniometer and expressed in degrees. Measurements were made for all joint actions: hip flexion (subject supine, knee flexed at $90^{\circ}$ ), extension (subject prone, knee extended), medial and lateral rotation (subject prone, knee flexed at $90^{\circ}$ ), abduction and adduction (subject supine, knee extended; hip flexed at $10^{\circ}$ for adduction); knee flexion (subject supine, hip flexed at $90^{\circ}$ ) and extension (subject supine, leg stretched). To enhance the reliability of the ROM measurements, the standard recommendations were followed. ${ }^{324}$ For each action, the protocol provided the starting position for subject and therapist, reference points for the pivot, and the distal points of the goniometer. The joint motion was continued until the action was completed or the pain threshold was reached. In the case of pain, the therapist identified its precise location. Pain in daily activities was measured using the Western Ontario and McMaster University (WOMAC) pain subscale, ${ }^{25}$ which is composed of five items and was used as a $100 \mathrm{~mm}$ visual analogue scale. Functional status in daily activities was assessed using the Lequesne index and WOMAC functional subscale, both of which are usually used in exploration of the lower limb OA. ${ }^{25} 26$ The Lequesne score is noted from 0 to 24 points, with 0 corresponding to normal function and 24 to a maximal handicap; the WOMAC functional subscale is composed of 17 items and was used with the Likert scale.

\section{Statistical analysis}

Normal distribution (Kolmogorov-Smirnov test) and homogeneity of variance (Fisher F test) were confirmed for each variable and allowed parametric statistics (Statview 5, Abacus, 1999). Statistical significance was accepted at $\mathrm{p}<0.05$. Students $t$ test was used to compare subject characteristics and passive ROM; the $\chi^{2}$ test (correction of Yates) was used to compare the incidence of hip OA. The Pearson correlation coefficient established the relation between ROM and OA, pain and JSW. The Mann-Whitney $\mathrm{U}$ test was used to compare the functional and pain values.

\section{RESULTS}

\section{Interview}

There were no cases of cartilage damage, surgery to the lower limbs, medication for the hip, or family medical antecedents of hip OA. The percentage of subjects reporting heavy work was higher in the control group than in the experimental 


\begin{tabular}{|llll|}
\hline Table 2 & Radiographic results from the Kellgren and Lawrence scale & \\
\hline Stage & Kellgren \& Lawrence criteria & $\begin{array}{l}\text { Handball } \\
\text { players }\end{array}$ & Controls \\
\hline 0 & Absence of osteophytes & & \\
1 & Doubtful osteophytes & 2 & 1 \\
2 & Minor osteophytes and/or subchondral sclerosis and/or osseous cysts & 8 & 3 \\
3 & Osteophytes and moderate decrease in JSW & 2 & 1 \\
4 & Osteophytes and large decrease in JSW & & \\
\hline JSW, Joint space width. & & \\
\hline
\end{tabular}

group: only $20 \%(\mathrm{n}=4)$ of the handball players had high exposure to physical loads compared with $51.2 \%(\mathrm{n}=21)$ of the control subjects. Two of the former handball players met the criteria for obesity, ${ }^{17}{ }^{18}$ with BMI $>30 \mathrm{~kg} / \mathrm{m}^{2}$; one was a former goalkeeper. Interestingly, neither showed any sign of hip OA. One control subject had a BMI $>30 \mathrm{~kg} / \mathrm{m}^{2}$, and the beginning of hip OA was observable.

\section{Hip radiographic examination}

A high incidence of hip OA was noted in the former elite handball players: $60 \%(n=12)$ were medically diagnosed with OA in at least one of the hip joints compared with 13\% $(\mathrm{n}=5)$ in the control group. This difference was significant $\left(\chi^{2}=11.07\right)$. Table 2 shows the results for the two groups obtained on the Kellgren and Lawrence radiographic classification. In the experimental group, the thickness of the joint cartilage was more altered in the left hip $(20-100 \%$ of the JSW) than in the right hip (20-50\% of the JSW). The concordance between the dominant leg and the side of hip OA was not significant ( $p=0.27)$. The decrease in JSW was most often located in the anterolateral quadrant $(n=6)$ and on the anterior $(\mathrm{n}=3)$ and posterior $(\mathrm{n}=2)$ wall of the acetabulum. Osteophytes were located on the posterior and anterior horns and under the fovea. Osseous cysts were located in the anterior superior part of the femoral head.
Clinical examinations and functional measurements Table 3 shows the values for passive ROM of the hip and knee. Hip flexion and medial rotation appeared significantly reduced (both hips) in the handball players compared with the ROM in the control group ( $p=0.03, p=0.02$ ). Extension, abduction, and lateral rotation were higher in the handball players $(\mathrm{p}=0.00, \mathrm{p}=0.01, \mathrm{p}=0.00)$. The adduction was distorted because it was combined with low flexion of the hip. The knee joint presented no deficit in either flexion or extension. Comparison of passive ROM between the hips with radiographic OA and healthy hips showed that flexion, adduction, and medial rotation were significantly higher in the healthy hips. Extension appeared higher in the hips with OA $(\mathrm{p}=0.00)$. A negative correlation was found between ROM in flexion and medial rotation and the severity of hip OA evaluated on the Kellgren and Lawrence scale $(\mathrm{p}=0.00, r=-0.85)$.

Table 4 shows the functional and pain status of the two groups. No significant differences were found between the Lequesne score and the WOMAC functional subscore of the players with OA compared with those of the controls with OA $(\mathrm{p}=0.057, \mathrm{p}=0.8)$. The Lequesne index and the WOMAC functional subscale indicated that the players with OA had difficulty going up and down stairs and getting in and out of cars. When pain was present, it was localised in the greater

\begin{tabular}{|c|c|c|c|c|c|c|}
\hline & \multicolumn{2}{|c|}{ Handball players $(n=20)$} & \multicolumn{2}{|c|}{ Controls $(n=39$ ) } & \multicolumn{2}{|c|}{ Total hips $(\mathrm{n}=118$ ) } \\
\hline & Right hip & Left hip & Right hip & Left hip & $\begin{array}{l}\text { OA hips } \\
\text { (n = 21) }\end{array}$ & $\begin{array}{l}\text { Healthy hips } \\
(\mathrm{n}=97)\end{array}$ \\
\hline \multicolumn{7}{|l|}{ Flexion $\left({ }^{\circ}\right)$} \\
\hline Mean (SD) & 111 (7) & $112(13)$ & $119(7)$ & $118(6)$ & $111(15)$ & $117(8)$ \\
\hline Range & $90-120$ & $70-120$ & $100-120$ & $100-120$ & $70-120$ & $90-120$ \\
\hline \multicolumn{7}{|l|}{ Extension $\left({ }^{\circ}\right)$} \\
\hline Mean (SD) & $13(8)$ & $12(9)$ & $4(2)$ & $5(3)$ & $11(10)$ & $6(6)$ \\
\hline \multirow{2}{*}{\multicolumn{7}{|c|}{$\begin{array}{l}\text { Range } \\
\text { Abduction ( }\end{array}$}} \\
\hline & & & & & & \\
\hline Mean (SD) & $40(6)$ & $39(7)$ & $28(4)$ & $28(4)$ & $34(11)$ & $32(7)$ \\
\hline Range & $30-50$ & $20-50$ & $20-35$ & $20-35$ & $20-50$ & $20-50$ \\
\hline \multicolumn{7}{|l|}{ Adduction ( $\left({ }^{\circ}\right)$} \\
\hline Mean (SD) & $22(10)$ & $22(11)$ & $24(4)$ & $25(5)$ & $19(8)$ & $25(7)$ \\
\hline Range & $10-40$ & $5-40$ & $20-30$ & $3-30$ & $5-40$ & $3-40$ \\
\hline \multicolumn{7}{|c|}{ Lateral rotation $\left({ }^{\circ}\right)$} \\
\hline Mean (SD) & $29(9)$ & $29(7)$ & $21(3)$ & $23(3)$ & $25(9)$ & $25(6)$ \\
\hline Range & $10-50$ & $10-40$ & $10-25$ & $20-30$ & $15-50$ & $10-50$ \\
\hline \multicolumn{7}{|c|}{ Medial rotation $\left({ }^{\circ}\right)$} \\
\hline Mean (SD) & $16(7)$ & $16(8)$ & $20(3)$ & $23(4)$ & $14(7)$ & $22(4)$ \\
\hline \multirow[t]{2}{*}{ Range } & $5-30$ & $0-30$ & $10-25$ & $10-30$ & $0-30$ & $10-30$ \\
\hline & Right knee & Left knee & Right knee & Left knee & & \\
\hline \multicolumn{7}{|l|}{ Flexion $\left({ }^{\circ}\right)$} \\
\hline Mean (SD) & $121(4)$ & $121(4)$ & $120(0)$ & $119(3)$ & & \\
\hline Range & $120-140$ & $120-140$ & $120-120$ & $110-120$ & & \\
\hline \multicolumn{7}{|l|}{ Extension ( $\left.{ }^{\circ}\right)$} \\
\hline Mean (SD) & 0 & 0 & 0 & 0 & & \\
\hline Range & 0 & 0 & 0 & 0 & & \\
\hline
\end{tabular}


trochanter and in the inguinal level. The handball players reported little pain during normal walking; however, rising from the seated position appeared to produce the most discomfort. Overall, the players with OA experienced minor pain in the hips, with a median value of 15 on the WOMAC pain subscale. This score did not correlate with the narrowing percentage of JSW $(p=0.09)$. The pain was significantly less in the players with OA than in the five controls with OA $(\mathrm{p}=$ 0.03 ).

In the controls with $\mathrm{OA}$, the Lequesne and WOMAC functional median values rose to 5 and 6 . The median value for pain was 70 for the subjects with OA. The Pearson correlation coefficient between pain and the narrowing percentage of JSW was significant for the controls with OA $(\mathrm{p}=0.00)$, and a high correlation was found $(r=0.92)$.

\section{DISCUSSION}

The results of this study indicate an association between elite handball practice and premature hip OA. When age, physical work, loading during a game, and BMI were taken into consideration, ${ }^{17}$ the results suggest an association between physical load and hip OA. The incidence of hip OA in the experimental group $(60 \%)$ was higher than in the control group (13\%). Our study thus clearly places intensive handball playing among other high risk activities such as soccer $(32 \%$, mean age of $47.6 i^{16} 49 \%$, mean age of $\left.56.1^{21}\right)$, fencing (35\%), ${ }^{27}$ rugby, and tennis $(16 \%) .^{28}$ The incidence of OA measured in the control group was similar to the values reported in the literature $(1-10 \%) .^{29-31}$

The type of sport, the length of time it has been practiced, and the playing level have all been suggested to contribute to the early appearance of hip OA..$^{32}$ The present study confirms this finding. Indeed, our study was made up of players with a lower mean age (44.9) than normal for developing hip OA (55-70). ${ }^{29-31}$ This observation supports the concept that elite and intense handball training may contribute to the appearance of hip OA. The risk of undergoing total hip replacement is increased 4.5 -fold after the age of 50 in athletes. ${ }^{32}$ This risk is increased in handball players because the joint loading measured during play is above the physiological limits of cartilage. ${ }^{19}$ Cartilage wear can also be the result of being overweight, ${ }^{18}$ but in the present study high BMI was not associated with hip OA. The accumulation of heavy loads, which strengthen muscles and ligaments, may decrease hip ROM, which is a characteristic sign of OA. ${ }^{1-}$

${ }^{4}$ The association between OA and BMI remains unclear. ${ }^{18}$ The OA noted in this study was mostly located anterolaterally. Handball thus seemed to cause a localised overload to the cartilage, contributing to its degradation. The repeated impacts to the anterior wall of the acetabulum and the tractions at the level of the posterior horn were probably responsible for the localisation of osteophytes. The

\section{What is already known on this topic}

- Elite handball players sustain specific loads to their lower limb joints throughout their careers

- Several sporting activities have been observed to be associated with the development of osteoarthritis of the hip

\section{What this study adds}

- Ex-elite handball players have a higher prevalence of premature osteoarthritis of the hip than age matched controls

- They show passive range of motion and pain level specific to the long term practice of handball

irregularities on the femoral head and the decrease in the JSW can be explained by a mechanical weakening of the bony and cartilaginous structures, reflecting an accumulation of micro-traumatic lesions. Once the process of $\mathrm{OA}$ is initiated, the primary functions of joint cartilage are altered and deterioration will not stop. ${ }^{8}$

Considering the hips with OA, the analysis of the passive ROM revealed evidence of joint stiffness in medial rotation and flexion, with the hip amplitude in rotation decreasing with disease aggravation. ${ }^{33}$ These amplitude values correlated negatively with the severity of OA. In the handball group, the high values for extension, abduction and lateral rotation may be explained by the frequent repetition of movements specific to the practice of handball.

The study showed few repercussions in terms of pain in the handball players, particularly in those with OA, indicating that the hip OA was well tolerated even with a score of 4 on the Kellgren and Lawrence scale. One explanation for the low rate of symptoms among players with OA may be that these subjects have developed a resistance to pain specific to the elite practice of handball. Indeed, the experience of pain during the career of elite athletes may increase the pain tolerance threshold. ${ }^{34}$ Only those movements requiring great amplitude in flexion were sources of functional disturbance, as indicated by the Lequesne and WOMAC functional scores.

We recognise that our study has limitations: it would be interesting to perform a prospective study with elite players to follow the eventual development or progression of the disease; the use of a questionnaire can never be totally valid and a degree of misclassification can occur in the collection of

Table 4 Functional and pain status of the subjects

\begin{tabular}{|c|c|c|c|c|}
\hline & \multicolumn{2}{|c|}{ Handball players } & \multicolumn{2}{|l|}{ Controls } \\
\hline & $\begin{array}{l}\text { Healthy } \\
(\mathrm{n}=8)\end{array}$ & $\begin{array}{l}O A \\
(n=12)\end{array}$ & $\begin{array}{l}\text { Healthy } \\
(n=34)\end{array}$ & $\begin{array}{l}\text { OA } \\
(n=5)\end{array}$ \\
\hline \multicolumn{5}{|l|}{ Score of Lequesne } \\
\hline Median (quartile 1, 3) & $0(0,0)$ & $2(2,3)$ & $0(0,2)$ & $5(4,9)$ \\
\hline Range & $0-0$ & $1-8$ & $0-2$ & $2-12$ \\
\hline \multicolumn{5}{|c|}{ WOMAC functional subscale } \\
\hline Median (quartile 1, 3) & $0(0,0)$ & $3(2,3)$ & $0.5(0,1)$ & $6(5,6)$ \\
\hline Range & $0-0$ & $1-7$ & $0-2$ & $3-7$ \\
\hline \multicolumn{5}{|l|}{ WOMAC pain subscale } \\
\hline Median (quartile 1, 3) & $0(0,0)$ & $15(0,32)$ & $0(0,0)$ & $70(30,80)$ \\
\hline Range & $0-0$ & $0-60$ & $0-0$ & $20-80$ \\
\hline
\end{tabular}


data; the number of handball players should be increased to strengthen the power of the results. However, this study underlines biological adaptations of the cartilaginous structure to the accumulation of mechanical loads using radiographs, ROM, and indexes.

\section{CONCLUSION}

Long term handball practice seems to have an effect on hip ROM and to be associated with the premature development of hip OA. However, the characteristic pain of OA was rarely observed in the handball players. There is sufficient evidence to warrant the implementation of further control measures including the development of preventive measures for young elite handball players as part of an overall risk management process. The use of shoes with special absorbing soles and changes in the schedule of young players would give them a better chance of reducing the effect of the excessive mechanical loads.

\section{Authors' affiliations \\ M L'Hermette, C Tourny-Chollet, CETAPS EA 3832, GRHAL, Rouen, France \\ G Polle, F Dujardin, GRHAL}

Competing interests: none declared

Ethical approval: $x$ ray examinations were performed systematically according to French law in the case of polytraumatisms.

\section{REFERENCES}

1 Kettunen JA, Kujala UM, Räty $H$, et al. Factors associated with hip joint rotation in former elite athletes. Br J Sport Med 2000:34:44-8.

2 Buckwalter JA, Lane NE. Athletics and osteoarthritis. Am J Sport Med 1997;25:873-81.

3 Steultiens MP, Dekker J, van Baar ME, et al. Range of motion and disability in patients with osteoarthritis of the knee or hip. Rheumatology 2000:39:955-61.

4 Vingärd E. Sport and the development of osteoarthrosis of the hip. Sports Med 1994;18:1-3

5 Lievense AM, Bierma-Zeinstra SM, Verhagen AP, et al. Influence of sporting activities on the development of osteoarthritis of the hip: a systematic review. Arthritis Rheum 2003:49:228-36.

6 Setton LA, Elliott DM, Mow VC. Altered mechanics of cartilage with osteoarthritis: human osteoarthritis and an experimental model of joint degeneration. Osteoarthr Cartil 1999;7:2-14.

7 Martin JA, Buckwalter JA. Articular cartilage aging and degeneration. Sports Med Arthrosc 1996:4:263-75.

8 Healy WL, loro R, Lemos MJ. Athletic activity after joint replacement Am J Sport Med $2001 ; 29: 377-88$.

9 Buckland-Wright C. Radiographic assessment of osteoarthritis: comparison between existing methodologies. Osteoarthr Cartil 1999;7:430-3.

10 Rovati LC. Radiographic assessment. Introduction: existing methodologies, Osteoarthr Cartil 1999;7:427-9.

11 Gehlsen G, Whaley M. Falls in the elderly. Part 2. Balance, strength, and flexibility. Arch Phys Med Rehabil 1990;71:739-41.

12 Lievense AM, Bierma-Zeinstra SM, Verhagen AP, et al. Influence of hip dysplasia on the development of osteoarthritis of the hip. Ann Rheum Dis 2004;63:621-6.

13 MacGregor AJ, Antoniades L, Matson M, et al. The genetic contribution to radiographic hip osteoarthritis in women. Result of a classic twin study. Arthritis Rheum 2000;43:2410-16.

14 Vingärd E, Alfredsson L, Goldie I, et al. Occupation and osteoarthrosis of the hip and knee: a register-based cohort study. Int J Epidemiol 1991;20:1025-31.
15 Lievense AM, Bierma-Zeinstra SM, Verhagen AP, et al. Influence of work on the development of osteoarthritis of the hip: a systematic review. J Rheumatol 2001;28:2520-8

16 Drawer S, Fuller CW. Propensity for osteoarthritis and lower limb joint pain in retired professional soccer players. Br J Sport Med 2001;35:402-8.

17 Cheng Y, Macera CA, Davis DR, et al. Physical activity and self-reported, physician-diagnosed osteoarthritis: is physical activity a risk factor? J Clin Epidemiol 2000;53:315-22.

18 Lievense AM, Bierma-Zeinstra SM, Verhagen AP, et al. Influence of obesity on the development of osteoarthritis of the hip: a systematic review. Rheumatology 2002;41:1155-62.

19 L'Hermette M, Tourny-Chollet C, Polle G, et al. Coxarthrosis and mechanical loads in handball playing. J Hum Movement Stud 2003;44:323-38.

20 Vingärd E, Alfredsson L, Malchau H. Osteoarthrosis of the hip in women and its relationship to physical load from sports activities. Am J Sport Med 1998;26:78-82.

21 Turner A, Barlow J, Heathcote-Elliot C. Long term impact of playing professional football in the United Kingdom. Br J Sport Med 2000;34:332-7.

22 Seil R, Rupp S, Tempelhof S, et al. Sports injuries in team handball. A oneyear prospective study of sixteen men's senior teams of a superior nonprofessional level. Am J Sport Med 1998;26:681-7.

23 Kellgren JH, Lawrence JS. Atlas of standard radiographs: the epidemiology of chronic rheumatism. Oxford: Blackwell Scientific Publications, 1963.

24 Klässbo M, Harms-Ringdahl K, Larsson G. Examination of passive ROM and capsular pattern in the hip. Physiother Res Int 2003;8:1-12.

25 Bellamy N, Buchanan WW, Goldsmith $\mathrm{CH}$, et al. Validation of WOMAC: a health status instrument for measuring clinically important patient relevant outcomes to antirheumatic drug therapy in patients with osteoarthritis of the hip or knee. J Rheumatol 1988;15:1833-40

26 Lequesne M. Coxarthrose. Rev praticien 2002;52:605-10.

27 Azémar G. Aspects traumatologiques spécifiques de l'escrime. J Traumatologie Sport 1999;16:114-6.

28 Demarais Y, Lequesne M. La hanche du sportif. Gaz Med Fr 1979;86:2969-72.

29 Danielsson L, Lindberg $\mathrm{H}$. Prevalence of coxarthrosis in an urban population during four decades. Clin Orthop 1997;342:106-10.

30 Hoaglund FT, Steinbach LS. Primary osteoarthritis of the hip: etiology and epidemiology. J Am Acad Orthop Surg 2001;9:320-7.

31 Jacobsen S, Sonne-Holm S, Soballe K, et al. Radiographic case definitions and prevalence of osteoarthritis of the hip: a survey of 4151 subjects in the Osteoarthritis Substudy of the Copenhagen City Heart Study. Acta Orthop Scand 2004:75:713-20.

32 Vingärd E, Alfredsson L, Goldie I, et al. Sports and osteoarthrosis of the hip. An epidemiologic study. Am J Sport Med 1993;21:195-200.

33 Dujardin $F$, Aucouturier T, Bocquet $G$, et al. Cinématique de la coxofémorale saine et arthrosique durant la marche. Rev Chir Orthop 1998;84:689-9.

34 Pen L, Fisher C. Athletes and pain tolerance. Sports Med 1994;18:319-29.

\section{........... COMMENTARY $\ldots \ldots \ldots \ldots$}

The authors of this well written paper have attempted to investigate and describe the passive hip and knee range of motion, the prevalence of radiological hip osteoarthritis, and the degree of hip pain in former elite handball players. The research results on the aetiological factors involved in the development of hip osteoarthritis are sometimes conflicting. Often several factors work together. All the knowledge we can obtain on the primary and secondary prevention of hip osteoarthritis and the associated disabilities is important.

Landstinget i Värmland, Säffle, Sweden; maria.klassbo@liv,se 